Please do not remove this page

RMIT

UNIVERSITY

\title{
Electric discharge grinding of polycrystalline diamond materials
}

Ding, Songlin; Mo, John; Brandt, Milan; Webb, Richard

https://researchrepository.rmit.edu.au/esploro/outputs/9921859385101341/filesAndLinks?institution=61RMIT_INST\&index=null

Ding, S., Mo, J., Brandt, M., \& Webb, R. (2013). Electric discharge grinding of polycrystalline diamond materials. Applied Mechanics and Materials, 271-272, 333-337.

https://doi.org/10.4028/www.scientific.net/AMM.271-272.333

Published Version: https://doi.org/10.4028/www.scientific.net/AMM.271-272.333

Repository homepage: https://researchrepository.rmit.edu.au

(C) (2013) Trans Tech Publications, Switzerland.

Downloaded On 2023/04/26 23:47:19 +1000

Please do not remove this page 
Thank you for downloading this document from the RMIT Research Repository.

The RMIT Research Repository is an open access database showcasing the research outputs of RMIT University researchers.

RMIT Research Repository: http://researchbank.rmit.edu.au/

\section{Citation:}

Ding, S, Mo, J, Brandt, M and Webb, R 2013, 'Electric discharge grinding of polycrystalline diamond materials', Applied Mechanics and Materials, vol. 271, no. Part 1, pp. 333-337.

See this record in the RMIT Research Repository at:

http://researchbank.rmit.edu.au/view/rmit:19494

Version: Accepted Manuscript

Copyright Statement: (c) (2013) Trans Tech Publications, Switzerland

Link to Published Version:

http://dx.doi.org/10.4028/www.scientific.net/AMM.271-272.333 


\title{
Electric Discharge Grinding of Polycrystalline Diamond Materials
}

\author{
Songlin Ding ${ }^{\mathrm{a}}$, John Mo ${ }^{\mathrm{b}}$, Milan Brandt ${ }^{\mathrm{c}}$, Richard Webb ${ }^{\mathrm{d}}$ \\ School of Aerospace, Mechanical and Manufacturing Engineering, RMIT University, Australia \\ asonglin.ding@rmit.edu.au, bjohn.mo@rmit.edu.au, milan.brandt@rmit.edu.au, \\ drichard.webb@rmit.edu.au
}

Keywords: Polycrystalline Diamond, PCD, EDM, EDG, Taguchi Method

\begin{abstract}
The poor electric conductivity of polycrystalline diamond (PCD) makes it difficult to machine with the conventional EDM process. Inappropriate selection of parameters of the power generator and the servo system leads to unstable working condition and low material removal rate. This paper introduces a method to find optimal parameters in the Electrical Discharge Grinding (EDG) of PCD materials with Taguchi method. The theory and detailed procedures are presented, experimental results are analyzed. The optimized configuration was validated through confirmation tests.
\end{abstract}

\section{Introduction}

The super-high hardness and excellent wear resistance properties of Polycrystalline Diamond (PCD) have led to the wide application of PCD tools in woodworking, automotive and aerospace industries [1]. Currently the PCD tools are fabricated either by directly sintering PCD materials inside the tool flank or by brazing PCD inserts which are cut from a PCD blank on the tool holder. Because diamond particles are non electric conductive, the conductivity of PCD is determined by the type and proportion of binding material which is usually Cobalt. The diameter of commercial PCD blanks can be up to $72 \mathrm{~mm}$.

Electrical Discharge Machining (EDM) is a well established non-contact machining method for the manufacturing of geometrically complex components and the shaping of hard-to-machine materials. The basic mechanism of EDM process has been studied for many years but it is not yet completely understood and is still an active research topic. Various researches in the Electrical Discharging Grinding (EDG) of PCD have been performed in the past decades [2,3,4]. Thoe et al. [5] examined the edge quality of various grades of PCD cutting tool blanks produced using an inhouse EDG machine. The pulse generator had a maximum current of $30 \mathrm{~A}$, was programmable with a resolution of $1 \mathrm{~A}$, had a maximum open circuit voltage of $150 \mathrm{~V}$, an Time-on/Time-off range of 1 $100 \mu \mathrm{s}$, and a minimum usable on-time of $6 \mu \mathrm{s}$. Olsen [6] studied the effects of operating parameters on sparked surface/edge quality and efficiency by using a commercial EDG machine. Taguchi experiments were used to find the optimized parameters. The voltage applied in their tests was in the range of $\mathrm{W} \times 102-1.7 \mathrm{~W} \times 102$, the current was $\mathrm{X} \times 10-1.5 \mathrm{X} \times 10$, the On-Time was $\mathrm{Y}-$ $2.0 \mathrm{Y}$ and Off-time $\mathrm{Z} \times 10-2.0 \mathrm{Z} \times 10$, where the values of $\mathrm{W}, \mathrm{X}, \mathrm{Y}$ and $\mathrm{Z}$ are unfortunately unavailable in the paper.

This paper introduces a method to find optimal parameters in the Electrical Discharge Grinding of PCD materials with Taguchi method. The theory and detailed procedures are presented, experimental results are analyzed. The optimized configuration was validated through confirmation tests

\section{Taguchi Method}

Design of Experiment (DOE) is to find the optimal settings of process parameters in order to identify the most influential factors, and minimize process variability and the effects of uncontrollable factors. Due to the large number of variables and their corresponding levels, it is impractical to apply full factorial DOE in practice. For example, the effects of eight factors need to 
be analyzed in our system design. Seven of the eight factors have 4 levels, while one factor has 2 levels. For such a design, the total number of experiments can be up to $2 \times 47=32768$, which indicates it is impossible to implement such experiments in industry considering the costs and the time consumed.

Taguchi method provides a simple way to design the experiments through the application of specially designed orthogonal arrays. In an orthogonal array all pair-wise combinations are evenly distributed. This guarantees all the pair-wise combinations are tested and creates a concise plan with much fewer experiments than full factorial DOE.

Based on the orthogonal, the optimized parameter settings can be bound by maximizing the objective function - signal-to-noise $(\mathrm{S} / \mathrm{N})$ ratio. Signal is the square of the mean value of the results; whereas noise is a measure of the variability of the response, it is caused by uncontrollable factors (noise factors).

Based on Taguchi Loss Function, the $\mathrm{S} / \mathrm{N}$ ration has three different mathematical expressions under three different situations: target is best, smaller is better, and larger is better.

1. Target is best

In these problems, when the mean becomes aero, the variance also becomes zero. We can use an adjustment factor to move the mean to target. The objective function to be maximized is:

$$
\mathrm{S} / \mathrm{N}=10 \log \frac{y^{2}}{z^{2}}
$$

where $\bar{y}$ and s denote the sample mean and sample standard deviation of the output.

2. Smaller is better

The desired value of result is zero. The objective function to be maximized is:

$$
\mathrm{S} / \mathrm{N}=-10 \log \left(\sum_{i=1}^{n} y_{i}^{2} / n\right)
$$

3. Larger is better

The target value is non-zero, as large as possible. The objective function to be maximized is:

$$
\mathrm{S} / \mathrm{N}=-10 \log \left(\left(\sum_{i=1}^{n}\left(1 / y_{i}^{2}\right)\right) / n\right)
$$

\section{Experimental Setup}

The PCD samples used in the experiments are CTB302 made by Element Six. The diamond particle size is $2 \mu \mathrm{m}$. The binding material is Cobalt. The workpiece were cut from the PCD disk with a cross section of $3.5 \mathrm{~mm} \times 1.6 \mathrm{~mm}$ (Fig. 1). The sample was fixed on a specially designed fixture (Fig.2) to guarantee that cutting area was constant for all the experiments.

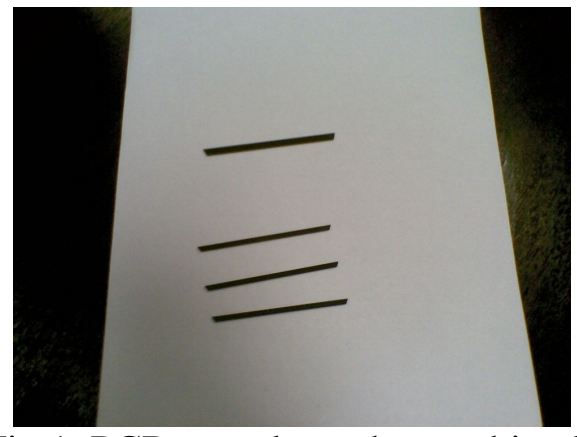

Fig 1. PCD samples to be machined

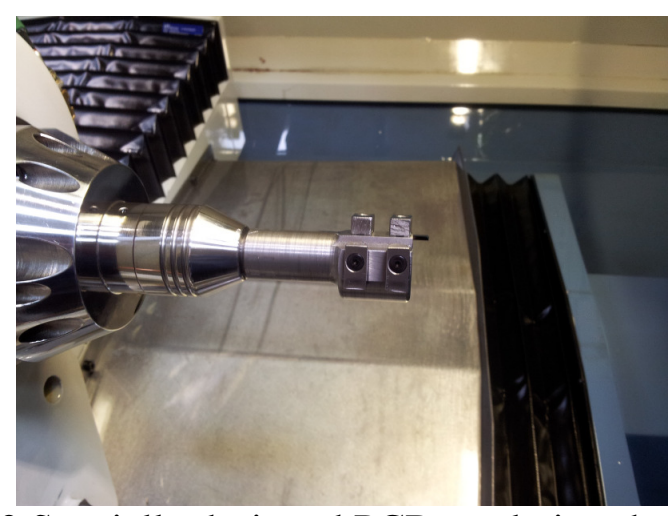

Fig. 2 Specially designed PCD workpiece holder. 


\section{Taguchi Experimental Design.}

In the EDG process, machining efficiency and process stability are affected by parameters not only of the electrical pulse generator but also of the CNC servo system of the machine tool.

Parameters of pulse generator that contribute to the efficiency and stability consist of voltage, current, Time-on, Time-off, polarity and the rotating speed of the electrode wheel. The response frequency of the CNC servo system is unchangeable once the system is built up. However, its response property can be adjusted through modifying the control curve of the CNC system. The nonlinear control curve is usually simplified by four or five control points. The shape of the control curve, or the positions of the control points, plays an important in the machining efficiency and the process stability.

Based on our experience, the optimized rotating speed of the wheel is around 500 RPM. The critical points of the control curve which affect the process most significantly are point e 3 and e4. The experimental parameters and their corresponding levels used to determine the optimized configurations are listed in Table 1.

Point e3 is defined by the voltage V3 and feed rate F3, as defined in the control chart; The federate of Point e4, F4, is defined based on the feed rate of point e3, F3, and a corresponding gradient, which has four levels: $0.1,0.2,0.3,0.4$.

Table 1 Experimental parameters

\begin{tabular}{|c|c|c|c|c|c|c|}
\hline Number & Parameter & $\begin{array}{c}\text { Number } \\
\text { of } \\
\text { levels }\end{array}$ & Level 1 & Level 2 & Level 3 & Level 4 \\
\hline 1 & Voltage & 2 & Low & High & & \\
\hline 2 & Current & 4 & & 8 & 12 & 16 \\
\hline 3 & T-on & 4 & 10 & 20 & 30 & 40 \\
\hline 4 & T-off & 4 & 10 & 20 & 30 & 40 \\
\hline 5 & Polarity & 2 & -1 & 1 & & \\
\hline 6 & V3 & 4 & 15 & 23 & 30 & 37 \\
\hline 7 & F3 & 4 & 0.15 & 0.23 & 0,3 & 0.37 \\
\hline 8 & F4 & 4 & F3+0.1 & F3+0.2 & F3+0.3 & F3+0.4 \\
\hline
\end{tabular}

The degree of freedom (DOF) of the overall mean is 1 . Without considering interactions, the total degree of freedom of this experiment is

$$
1+1+3+3+3+1+3+3+3=21
$$

Therefore, the most suitable orthogonal array should be L25.

Since the levels of 6 factors in this experiment are 4, L25 is unable to provide such an array. The only applicable array is L32. L32 suits an experiment of 1 factor with 2 two levels, and 7 factors with 4 levels.

Based on the uniform principle, the levels of polarity can be assigned as 1,0 1,0. The L32 Taguchi orthogonal array and experiment results are shown in Table 2.

The Material Remove Rate (MRR) here is described as feed rate because the area of cross section of the workpiece is fixed in all experiments. It is the ratio of material removed in volume over the area of cross section of the workpiece.

To describe the stability of the process, machining status is quantified in 7 levels, as shown in Table 3. 
Table 2 L32 Taguchi orthogonal array

\begin{tabular}{|c|c|c|c|c|c|c|c|c|c|}
\hline Voltage & Current & T-On & T-Off & Polarity & V3 & F3 & $\mathrm{F} 4$ & MRR & Stability \\
\hline Low & 4 & 10 & 10 & 1 & 15 & 0.15 & $\mathrm{~F} 3+0.1$ & 0.051638 & 3 \\
\hline Low & 4 & 20 & 20 & 0 & 23 & 0.23 & $\mathrm{~F} 3+0.2$ & 0.003666 & 6 \\
\hline Low & 4 & 30 & 30 & 1 & 30 & 0.3 & $\mathrm{~F} 3+0.3$ & 0.050842 & 4 \\
\hline Low & 4 & 40 & 40 & 0 & 37 & 0.37 & $F 3+0.4$ & 0.002231 & 4 \\
\hline Low & 8 & 10 & 10 & 0 & 23 & 0.3 & $\mathrm{~F} 3+0.3$ & 0.005649 & 5 \\
\hline Low & 8 & 20 & 20 & 1 & 15 & 0.37 & $\mathrm{~F} 3+0.4$ & 0.062338 & 2 \\
\hline Low & 8 & 30 & 30 & 0 & 37 & 0.15 & $\mathrm{~F} 3+0.1$ & 0.004867 & 5 \\
\hline Low & 8 & 40 & 40 & 1 & 30 & 0.23 & $\mathrm{~F} 3+0.2$ & 0.069174 & 4 \\
\hline Low & 12 & 10 & 20 & 1 & 37 & 0.15 & $\mathrm{~F} 3+0.2$ & 0.080506 & 4 \\
\hline Low & 12 & 20 & 10 & 0 & 30 & 0.23 & $\mathrm{~F} 3+0.1$ & 0.012785 & 6 \\
\hline Low & 12 & 30 & 40 & 1 & 23 & 0.3 & $F 3+0.4$ & 0.128636 & 4 \\
\hline Low & 12 & 40 & 30 & 0 & 15 & 0.37 & $\mathrm{~F} 3+0.3$ & 0.009349 & 4 \\
\hline Low & 16 & 10 & 20 & 0 & 30 & 0.3 & $\mathrm{~F} 3+0.4$ & 0.015817 & 4 \\
\hline Low & 16 & 20 & 10 & 1 & 37 & 0.37 & $\mathrm{~F} 3+0.3$ & 0.060278 & 3 \\
\hline Low & 16 & 30 & 40 & 0 & 15 & 0.15 & $F 3+0.2$ & 0.01072 & 6 \\
\hline Low & 16 & 40 & 30 & 1 & 23 & 0.23 & $\mathrm{~F} 3+0.1$ & 0.121154 & 4 \\
\hline High & 4 & 10 & 40 & 1 & 37 & 0.23 & $\mathrm{~F} 3+0.3$ & 0.042191 & 2 \\
\hline High & 4 & 20 & 30 & 0 & 30 & 0.15 & $\mathrm{~F} 3+0.4$ & 0.006402 & 2 \\
\hline High & 4 & 30 & 20 & 1 & 23 & 0.37 & $\mathrm{~F} 3+0.1$ & 0.087733 & 2 \\
\hline High & 4 & 40 & 10 & 0 & 15 & 0.3 & $\mathrm{~F} 3+0.2$ & 0.005531 & 1 \\
\hline High & 8 & 10 & 40 & 0 & 30 & 0.37 & $\mathrm{~F} 3+0.1$ & 0.009207 & 2 \\
\hline High & 8 & 20 & 30 & 1 & 37 & 0.3 & $F 3+0.2$ & 0.14 & 2 \\
\hline High & 8 & 30 & 20 & 0 & 15 & 0.23 & $\mathrm{~F} 3+0.3$ & 0.004483 & 5 \\
\hline High & 8 & 40 & 10 & 1 & 23 & 0.15 & $\mathrm{~F} 3+0.4$ & 0.084912 & 2 \\
\hline High & 12 & 10 & 30 & 1 & 15 & 0.23 & $F 3+0.4$ & 0.081951 & 2 \\
\hline High & 12 & 20 & 40 & 0 & 23 & 0.15 & $\mathrm{~F} 3+0.3$ & 0.015484 & 5 \\
\hline High & 12 & 30 & 10 & 1 & 30 & 0.37 & $\mathrm{~F} 3+0.2$ & 0.056213 & 7 \\
\hline High & 12 & 40 & 20 & 0 & 37 & 0.3 & $\mathrm{~F} 3+0.1$ & 0.018255 & 3 \\
\hline High & 16 & 10 & 30 & 0 & 23 & 0.37 & $\mathrm{~F} 3+0.2$ & 0.032903 & 3 \\
\hline High & 16 & 20 & 40 & 1 & 15 & 0.3 & $\mathrm{~F} 3+0.1$ & 0.102754 & 3 \\
\hline High & 16 & 30 & 10 & 0 & 37 & 0.23 & $\mathrm{~F} 3+0.4$ & 0.050973 & 2 \\
\hline High & 16 & 40 & 20 & 1 & 30 & 0.15 & $\mathrm{~F} 3+0.3$ & 0.222162 & 4 \\
\hline
\end{tabular}

Table 3 Quantified level of machining stability

\begin{tabular}{|c|c|c|c|c|c|c|}
\hline Smooth & $\begin{array}{c}\text { Near } \\
\text { Smooth }\end{array}$ & $\begin{array}{c}\text { Little } \\
\text { Rough }\end{array}$ & Rough & Spikey & $\begin{array}{c}\text { Spikey \& } \\
\text { Rough }\end{array}$ & Dangerous \\
\hline 1 & 2 & 3 & 4 & 5 & 6 & 7 \\
\hline
\end{tabular}

\section{Results and Discussion}

Because our objective is to achieve the largest material remove rate, the rule "larger is better" is used in the calculation. The ANOVA results achieved by using MiniTab (Edition 16) are shown in Table 4. These results provide us with the information of the significance of each factor, and the rank of contributions each fact made to the results.

From Table 4, it can be seen that Polity is the most significant factor. To achieve high MRR, positive polity should be applied. T-on and T-off, and the duty cycle are less important than current and voltage in the EDG process; in other words, they contribute less to the material remove rate compared to current and voltage. A change in the values of duty cycle has a slighter effect on MRR than the change in current and voltage. 
Table 4 Results of ANOVA

$\begin{array}{lrrrrrrrrr}\text { Level } & \text { Voltage } & \text { Current } & \text { T-On } & \text { T-Off } & \text { Polarity } & \text { V3 } & \text { F3 } & \begin{array}{r}\text { F4 } \\ \text { (Gradient) }\end{array} \\ 1 & -33.01 & -36.38 & -31.02 & -31.30 & -40.63 & -32.93 & -30.98 & -30.57 \\ 2 & -29.37 & -33.09 & -31.50 & -30.83 & -21.75 & -29.78 & -31.27 & -31.26 \\ 3 & & -29.48 & -31.04 & -30.42 & & -30.70 & -30.18 & -32.44 \\ 4 & & -25.81 & -31.19 & -32.20 & & -31.35 & -32.33 & -30.48 \\ \text { Delta } & 3.64 & 10.57 & 0.48 & 1.78 & 18.87 & 3.15 & 2.15 & 1.96 \\ \text { Rank } & 3 & 2 & 8 & 7 & 1 & 4 & 5 & 6 & \text { F4 } \\ \text { Response Table for Means } & & & & & & & & & \\ \text { Level } & \text { Voltage } & \text { Current } & \text { T-On } & \text { T-0ff } & \text { Polarity } & \text { V3 } & \text { F3 } & \text { (Gradient) } \\ \text { 1 } & 0.04310 & 0.03128 & 0.03998 & 0.04100 & 0.01302 & 0.04110 & 0.05959 & 0.05105 \\ 2 & 0.06007 & 0.04758 & 0.05046 & 0.06187 & 0.09016 & 0.06002 & 0.04830 & 0.04984 \\ 3 & & 0.05040 & 0.04931 & 0.05593 & & 0.05533 & 0.05844 & 0.05130 \\ 4 & & 0.07710 & 0.06660 & 0.04755 & & 0.04991 & 0.04003 & 0.05416 \\ \text { Delta } & 0.01697 & 0.04582 & 0.02661 & 0.02087 & 0.07714 & 0.01892 & 0.01955 & 0.00432 \\ \text { Rank } & 7 & 2 & 3 & 4 & & 1 & 6 & 5 & 8\end{array}$

The S/N ratio of main effects is plotted in Fig.3. It can be seen that the gradient of voltage, current and Polarity are larger, which indicates the effects of these parameters are more significant; while T-on, T-off, and the rest are relative flat in the figure, which indicates these parameters contribute less to the MRR. This matches the results from ANOVA. According to Figure EEE, the highest MRR will occur with the combination of parameters shown in Table 5. The predicated MRR is 0.167286 .

Table 5, Predicted result of MRR

\begin{tabular}{|c|c|c|c|c|c|c|c|c|}
\hline Voltage & Current & T-On & T-Off & Polarity & V3 & F3 & F4 & Predicted MRR \\
\hline High & 16 & 40 & 20 & 1 & 23 & 0.3 & F3 +0.4 & 0.167286 \\
\hline
\end{tabular}

According to Table 3, the most unstable status of the process is "7", a smooth process is " 1 ". Because we desired to achieve a smooth process, the rule "smaller is better" was used in MiniTab analyze stability. It was found that voltage, current and F4 were the most significant in determining the stability of the process. T-on and V3 were less important. This indicates that a change in voltage, current or F4 will have more effect in the process stability than the change in T-on and V3.

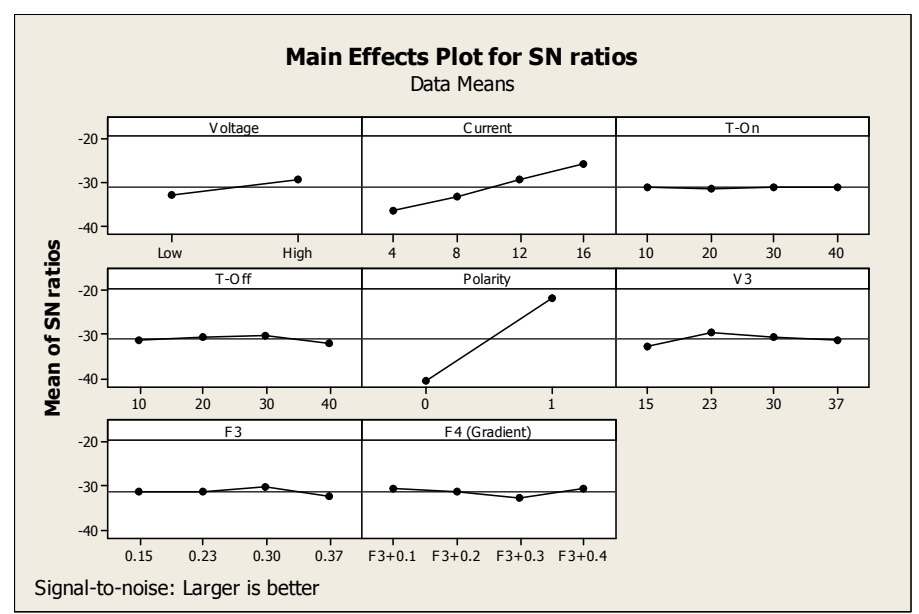

Fig. 3 MRR Main Effects for S/N ratios (Larger the better)

The S/N ratio of main effects is plotted in Fig.4. It can be seen the gradient of voltage, current and F4 are sharper, which indicates the effects of these parameters are significant; while T-off, Polarity, and F3 are relative flat, which indicates a change in the values of these parameters will cause less chance of instability compared with the first three parameters. 
To validate the predicated results, a confirmation test were conducted. By using setup in Table 5, the MRR achieved in the test is 0.19464286 . This is a bitter higher than the predicted value, while the stability is spiky and rough.

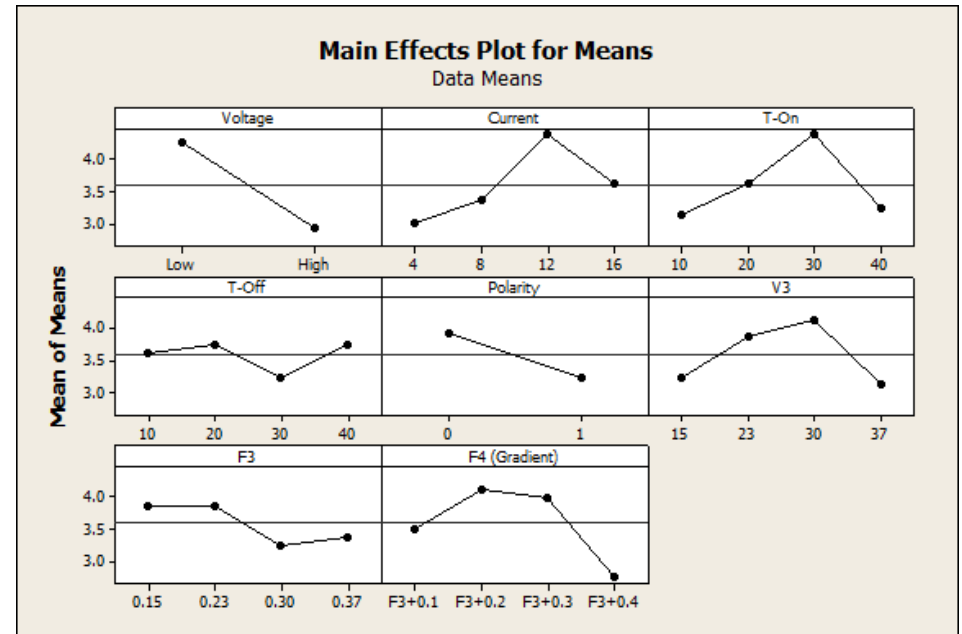

Fig.4 Stability main effects plot for mean (Smaller the better)

\section{Conclusions}

This paper presented the application of Taguchi method to find optimal parameters in Electrical Discharge Grinding of PCD materials. The theory and detailed procedures are introduced. From experiment results it is found that the Polity is the most significant factor. To achieve high MRR, positive polity should be applied. T-on and T-off, and the duty cycle are less important than current and voltage in the EDG process. A change in the values of duty cycle has a slighter effect on MRR than the change in current and voltage.

\section{Acknowledgment}

This research was supported by Advanced Manufacturing Corporate Research Centre under the Australian Government's Cooperative Research Centres Program as Project No. 2.2.1.

\section{Reference}

[1] S. Ye, W. Pan, S. Ding, J, Mo, M. Brandt and A. Mackie: Advanced Materials Research Vol. 426 (2012) p. 44

[2] T. Masaki, T.Kuriyagawa , J. Yan, N. Yoshihara: International Journal of Surface Science and Engineering, Vol. 1(2007), p.344

[3] M.J. Haddad, A. Fadaei Tehrani: Journal of Material Processing Technology Vol. 199 (2008), p.3690

[4] M.Mahardika, G.S. Prihandanna, T.Endo, T.Tsujimoto, N.Matsumot, B.Arifvianto, K.Mitsui: Int J Adv. Manuf Technol Vol. 60 (2012), p.985

[5] T.B. Thoe, D.K. Aspinwall, M.L.H. Wise and I.A.Oxley Journal of Material Processing Technology Vol. 56 (1996), p.773

[6] R. H. Olsen, D.K. Aspinwall and R.C.Dewes: Journal of Materials Processing Technology Vol. 155-156 (2004), p.1227 